\title{
CASOS MÁS FRECUENTES EN EL TRIBUNAL CONSTITUCIONAL
}

Felipe Paredes San Román ${ }^{1}$

\section{RESUMEN}

El presente artículo, de carácter introductoria, aspira a constituirse en una suerte -algo arbitraria- de guía que identifique algunos de los casos que, con mayor habitualidad, se someten a consideración del TC en el cumplimiento de su función de conocer las resoluciones denegatorias en segunda instancia judicial de las acciones de garantía, para lo cual se dividirá el tratamiento en hábeas corpus, acciones de amparo laboral, amparos previsionales, amparos contra resoluciones judiciales y otros, acciones de cumplimiento y hábeas data.

\section{PALABRAS CLAVES:}

Tribunal Constitucional. Hábeas Corpus. Amparo laboral. Amparo Previsional. Hábeas Data. Acción de Cumplimiento.

\section{ABSTRACT}

This introductory article is aimed at becoming a sort of guide to identify some of the most frequent motions of appeal brought before the Constitutional Court in performing its duties to examine second instance decisions denying court protective measures. To this end, the article examines habeas corpus, actions seeking constitutional protection on labor matters, pension protections, appeals against judgments and the like, enforcement and habeas data.

\section{KEY WORDS}

Constitutional Court. Habeas Corpus. Actions seeking constitutional protection on labor matters. Pension Protection. Habeas Data. Enforcement Petition.

\section{Delimitación del ASUNTO A TRATAR}

Como se sabe el Tribunal Constitucional peruano (en adelante, el TC) está habilitado para conocer: i) los procesos de inconstitucionalidad interpuestos contra normas de rango legal en atención a que éstas habrían vulnerado la Constitución por la forma o el fondo, ii) los procesos competenciales que un poder del Estado o un órgano constitucionalmente autónomo interpone en contra de un homólogo a él, respecti- vamente, dado que existe un conflicto de competencia entre uno y otro, y iii) las resoluciones denegatorias en segunda instancia judicial de las siguientes acciones de garantía: hábeas corpus, acciones de amparo, acciones de cumplimiento y hábeas data, puesto que el proceso de acción popular se tramita íntegramente ante el Poder Judicial.

\section{HáBEAS CORPUS}

El proceso de hábeas corpus está diseñado para proteger el derecho a la libertad personal, de modo tal que si una persona no está detenida ni su ejercicio de la libertad individual afronta restricciones tenemos entonces que una eventual demanda de hábeas corpus se declarará improcedente.

En efecto, si se sigue un proceso penal en contra del demandante habiéndose dictado mandato de detención al momento de dictarse el auto de apertura de instrucción, sí resultará procedente, en principio, la demanda de hábeas corpus.

1 Profesor de Derecho Constitucional y Procesal Constitucional de la UNIFE. Jefe del Gabinete de Asesores del Tribunal Constitucional. 
Igual situación ocurrirá en caso de dictarse un mandato de comparecencia restringida en que, si bien no se le priva de libertad al recurrente, eventualmente sí se le puede estar restringiendo el ejercicio de su libertad de tránsito, como acontece con aquellos a quienes se les impide desplazarse fuera del territorio nacional sin autorización del juez de la causa penal.

Por esta razón es fundamental advertir la condición procesal del recurrente pues puede ser que afronte un proceso penal, pero que no lo haga como detenido sino en libertad, producto de haber recaído sobre él mandato de comparecencia simple o por haberse producido la sustracción de la materia.

Es muy frecuente que al momento de interponerse la demanda de hábeas corpus, el recurrente sea víctima de una detención policial o de una detención preventiva (dictada por el juez cuando se dicta el auto de apertura de instrucción) o de una detención judicial (dictada por el juez o la Sala Penal cuando se dicta sentencia), mas con el devenir del proceso suele ocurrir algunos de los siguientes supuestos:

i) Que ya no esté vigente la detención policial y que el recurrente haya recuperado su libertad.

ii) Que el recurrente ya no esté detenido por orden policial, sino por mandato judicial, esto es, que el juez dictó mandato de detención, por lo que es válido sostener que su detención ya no es policial, sino judicial en mérito a un mandato que, por cierto, no ha sido cuestionado en la demanda.

iii) Que la detención preventiva ya no esté vigente pues el juez penal ha variado el mandato de detención por el mandato de comparecencia.

iv) Que la detención preventiva haya devenido definitiva, lo que se da cuando el juez expide sentencia y condena al recurrente a pena privativa de la libertad, con lo cual carece de objeto pronunciarse respecto de la detención preventiva contenida en el auto de apertura de instrucción, pues lo que está produciendo efectos es la sentencia que ha ordenado su detención.

v) Que la segunda instancia judicial haya revocado o declarado nula la sentencia dictada en primer grado que dispuso la detención del recurrente, disponiendo su libertad.

En cualquiera de estos supuestos cabe señalar que si bien al momento de interponerse la demanda se cumplía con el requisito de procedibilidad del hábeas corpus (privación de libertad) posteriormente esta condición ya no se cumple, por lo que es de aplicación la previsión estipulada en el segundo párrafo del artículo $1^{\circ}$ del Código Procesal Constitucional (en adelante, el C.P.Const.).

Distinto es el caso que se da cuando al momento de interponerse la demanda de hábeas corpus el recurrente goza de libertad, como ocurre con el agraviado en un proceso penal disconforme con el accionar del juez que no dicta mandato de detención en contra del procesado. El agraviado nunca se ha visto privado de su libertad, por lo que será de aplicación el artículo $5.5^{\circ}$ del Código Procesal Constitucional que regula un supuesto diferente al que anteriormente vimos con ocasión del artículo $1^{\circ}$ del Código adjetivo citado. El Art. $5.5^{\circ}$ se aplica en el caso de que el recurrente esté libre antes de la demanda, el Art. $1^{\circ}$, en cambio, se aplica en el caso de que después de la demanda el recurrente haya recuperado su libertad.

Nótese, por otra parte, que una constante en la enumeración descrita líneas arriba de supuestos es que la privación de libertad de una persona obedece a un mandato judicial y no fiscal. Sucede que es muy común toparse con demandas en las que se denuncia el proceder de los representantes del Ministerio Público alegando algún acto irregular como la interposición de una denuncia que carece de congruencia entre los hechos y el petitorio, o de no haber notificado al recurrente para que pueda recibir su manifestación ante el fiscal, entre otras causales. Pues bien esas demandas se declaran invariablemente improcedentes dado que el fiscal carece de facultades para restringir la libertad personal de la persona procesada y es que su actividad es postulatoria y no decisoria, como sí es la del juez.

Lo expuesto precedentemente no equivale a sostener que el accionar del fiscal está exonerado de responsabilidad en lo que concierne al proceso de hábeas corpus; sí la tiene en caso se de- 
nuncie un proceder manifiestamente arbitrario que implicaría solicitar la interdicción de dicho comportamiento arbitrario. Sin embargo, por su naturaleza excepcional, este caso escapa al objeto que se ha delimitado en esta entrega.

Luego de habernos referido a la premisa que orienta el proceso de hábeas corpus (que el recurrente esté privado de su libertad), conviene evaluar que la resolución judicial que vulnera ese derecho ostente la calidad de firme, es decir, que no sea legalmente admisible la interposición de un recurso impugnatorio que sea capaz de revertir los efectos de la decisión judicial que restringió la libertad individual. En razón de ello no proceden las demandas que cuestionan resoluciones que son susceptibles de apelación en sede penal.

Ahora bien si, pese a que cabe la posibilidad de apelar y el recurrente no lo ha hecho o que la apelación se ha rechazado por haberse interpuesto fuera del plazo legal para hacerlo, el TC entiende, extendiendo la regulación prevista para la acción de amparo en el artículo $4^{\circ}$ del Código Procesal Constitucional, que el recurrente ha consentido la resolución que alega le causa agravio y por lo tanto tampoco procede recurrir a sede constitucional para objetar una materia que debió ser discutida en sede penal. En rigor, desde mi punto de vista, en este último supuesto no estamos ante un supuesto de falta de firmeza, sino ante un supuesto de improcedencia por consentimiento del recurrente, aunque en uno y otro caso reconozcamos la causal de improcedencia contenida en el artículo $4^{\circ}$ del Código Procesal Constitucional.

El hábeas corpus también resultará improcedente en el supuesto de que se recurra a la jurisdicción constitucional para discutir asuntos de mera legalidad, propios de la jurisdicción penal, como son el juicio de culpabilidad del recurrente, la tipificación efectuada por el juez respecto del delito imputado al recurrente o la valoración de las pruebas desplegadas en el proceso penal subyacente, siendo de aplicación el artículo $5.1^{\circ} \mathrm{del}$ Código Procesal Constitucional.

\section{ACCIONES DE AMPARO LABORAL}

El amparo laboral suele perseguir la reposición del recurrente en el centro de trabajo del que alega haber sido despedido arbitrariamente (ya sea despido incausado, despido fraudulento o despido nulo), al haberse violado su derecho al trabajo.

A partir del precedente vinculante contenido en el caso Baylón (Exp. 206-2005-AA/TC) se delimitó la procedencia del amparo laboral para aquellos casos en los que se discute la constitucionalidad del despido de un trabajador que pertenece al régimen laboral de la actividad privada regida por el Decreto Legislativo $N^{\circ} 728$, derivándose al proceso contencioso-administrativo aquellos casos en los que el trabajador pertenece al régimen laboral de la actividad pública regida por el Decreto Legislativo $\mathrm{N}^{\circ}$ $\underline{276}$.

Tenemos entonces que en los casos en que un trabajador adscrito al régimen laboral público como son, a título de ejemplo, los trabajadores de los gobiernos locales -salvo los obreros que se dedican a labores de limpieza de la ciudad- y regionales, los policías, los militares, los profesores que no han ingresado a la carrera pública magisterial, los empleados de los ministerios, busca su reposición, deben tramitar su pretensión en el proceso contencioso-administrativo y no en el amparo laboral.

Como toda regla, ésta tiene su excepción. Procede el amparo laboral en caso se alegue un despido discriminatorio de un trabajador del D.Leg. 276 o ante una reclamación colectiva sostenida por una organización sindical.

Por otra parte, el régimen de contratación administrativa de servicios (en adelante, el CAS) al que están adscritos numerosos trabajadores en la administración pública fue definido por el TC como un régimen laboral especial, razón por la cual no se ajustan a la doctrina jurisprudencial expedida por el TC aquellos pronunciamientos judiciales que optan por declarar improcedente el amparo interpuesto por un recurrente que ha suscrito un CAS y que ha sido víctima de un despido, pues no es constitucionalmente aceptable equiparar el tratamiento jurídico dispensado al CAS con el dispensado al régimen del D.Leg. 276 , en el que sí es improcedente el amparo laboral.

En los casos de los trabajadores CAS corresponde ingresar a un examen de fondo, siendo frecuente encontrar casos en que la causa del cese laboral radica en el vencimiento del contrato del trabajador, de ahí que se 
declaren infundadas las demandas que alegan un despido incausado en este supuesto.

Ahora bien debe señalarse que el itinerario laboral del recurrente suele haberse iniciado bajo el régimen de contratación civil por locación de servicios (o servicios no personales, como se denomina en el Estado) y luego continuado bajo el régimen CAS. En estos casos el TC, invariablemente, reserva su objeto de evaluación al período de servicios en los que el recurrente trabajó como CAS, considerando que este contrato se declaró constitucional, no siendo objeto de evaluación el período laborado como SNP en el entendido de que la relación nominalmente civil y presuntamente laboral ya se laboralizó en virtud de la suscripción del CAS.

No obstante la constatación de un despido arbitrario, otro supuesto de improcedencia del amparo laboral es la insuficiencia de los medios probatorios existentes en el expediente, los que no evidencian un agravio manifiesto del derecho al trabajo del recurrente, de ahí que sea necesario acudir a la sede laboral para la actuación de pruebas como pericias, testimonios, entre otras, que están vedadas, cuando éstas dilatan el proceso, en las acciones de garantía, como lo recuerda el artículo $9^{\circ}$ del Código Procesal Constitucional.

Este artículo es invocado por el TC en los casos en que existen hechos contradictorios respecto del despido, como ocurre en los denominados despidos disciplinarios en los que para el recurrente se ha producido un despido fraudulento, mientras que la entidad emplazada alega haber respetado el procedimiento establecido por la norma laboral para el despido de un trabajador.

Al momento de revisar un amparo laboral se impone confirmar que la demanda se haya interpuesto dentro del plazo previsto en el artículo $44^{\circ}$ del Código Procesal Constitucional, esto es, 60 días hábiles después de ocurrido el despido (acto lesivo), pues caso contrario se tendría que declarar improcedente la demanda por extemporánea. Sobre el particular merece subrayarse que el referido plazo, en principio, no se interrumpe, de ahí que no son aceptables las alegaciones de que la eventual interposición de demandas ordinarias (impugnación de despido en sede laboral o acción contencioso administrativa) interrumpan el plazo prescriptorio.

Igualmente debe verificarse que la demanda de amparo laboral respeta la competencia territorial establecida por la normativa. Son numerosos los casos en que los trabajadores interponen la demanda en un juzgado que no se condice con el domicilio del recurrente (para lo cual uno se vale del domicilio consignado en el DNI o de aquella dirección consignada en el expediente a ser examinado) ni con el domicilio de la entidad demandada.

Al respecto es conveniente estar particularmente atentos a la creación de juzgados por parte del Poder Judicial, pues podría ocurrir, como ha ocurrido (juzgado de Ventanilla en el Callao), que la sede de la entidad demandada se correspondía inicialmente con el juzgado de una ciudad para luego de creado un juzgado en un distrito particular, la sede de la entidad demandada coincida con el ámbito de acción del juzgado recién creado en dicho distrito.

La desnaturalización de los contratos modales es frecuentemente invocada en los amparos laborales. Se sostiene que los empleadores, en su afán de encubrir una relación laboral a plazo indeterminado, obligan a sus trabajadores a suscribir contratos sujetos a modalidad, como por ejemplo contrato para obra determinada o servicio específico, contrato por inicio de actividad, entre otros, pero en los hechos se configura un contrato indeterminado en función del principio de primacía de la realidad.

Dos son los aspectos básicos que se suelen presentar en los expedientes referidos a contratos modales. Primero, la naturaleza de las funciones para las cuales se contrata. Si éstas son permanentes (por ejemplo, constan en el Reglamento de Organización y Funciones - ROF o en el Manual de Organización y Funciones - MOF de la entidad, o al trabajador se le ha asignado una plaza en el Cuadro para Asignación de Personal - CAP) así se califiquen como de eventuales, es obvio que la función es permanente y por ende, habría operado la desnaturalización alegada.

En segundo término debe examinarse la causa objetiva que provocó la contratación. No se trata simplemente de invocar el nomen iuris del contrato, sino de explicitar en qué consiste el servicio específico que se ha contratado, o cuál es la nueva 
actividad que se ha iniciado en la entidad demandada, para seguir con los ejemplos mencionados. Así, si una empresa que antes tercerizaba determinada actividad, decide hoy asumirla como una función adicional que se incorpora a su giro comercial, estamos ante un caso claro de una nueva actividad para la cual tendrá que contratar personal bajo modalidad.

Sobre este último punto es conveniente referirse a los contratos de exportación de productos no tradicionales. Como quiera que este contrato es sumamente flexible, en la medida que no está sujeto a un período máximo de contratación (a diferencia de los contratos modales que tienen como límite un plazo de 5 años), el TC es riguroso en confirmar que cada acto de renovación de contrato obedece a un contrato específico de exportación que se debe atender por parte de la empresa, de ahí que si no se advierte de la causa objetiva de contratación se presume que estamos ante una relación laboral indeterminada.

Finalmente, en las sentencias que amparan la pretensión solicitada (reposición, en su gran mayoría) se declara improcedente, de ser el caso, la pretensión del pago de las remuneraciones dejadas de percibir. La razón es que el amparo solo reconoce derechos, no es constitutivo de derechos, de modo tal que no es la vía idónea para generar un derecho del que antes no se gozó, sino que lo es para restablecer su ejercicio tal como ocurría en el estado de cosas previo a la vulneración constitucional, tal como prescribe el Art. $1^{\circ}$ del C.P.Const.

\section{ACCIONES DE AMPARO PREVISIONAL}

Los amparos previsionales se presentan fundamentalmente para la plena concreción del derecho a la pensión. Especialmente llegan a conocimiento del TC casos derivados del Decreto Ley 19990 que en términos generales reconoce el derecho a la pensión de jubilación y el derecho a la pensión por invalidez.

El TC ha establecido que no procede vía amparo la solicitud de reajuste de la pensión de jubilación que es igual o superior a la pensión mínima (que a la fecha de redacción de esta entrega asciende a $S / .415 .00$ ) y siempre que no se requiera de tutela de urgencia, pues puede darse el caso de una persona que, al adolecer de un grave estado de salud, le urge el esclarecimiento de la controversia a través del pronunciamiento de la jurisdicción constitucional.

Tampoco proceden los casos en los que se busca acreditar los años de aportaciones necesarios para obtener una pensión, mediante documentación que no es considerada idónea por el TC, como se precisó en la STC 4762-2007-PA/TC y en su resolución aclaratoria. Para acreditar años de aportaciones debe presentarse documentación (v.gr. boletas de pago) debidamente corroborada con otra (v.gr. certificados de trabajo, libros de planillas o liquidaciones de tiempo de servicios) ya sea en original o en copia legalizada o fedateada, que pruebe el periodo laboral trabajado.

En razón de ello, la presentación de documentación distinta a la reseñada precedentemente (v.gr. una declaración jurada del recurrente) obligará al juzgador constitucional a desestimar la demanda dejando a salvo su derecho para que acuda a la vía ordinaria para obtener su pensión, en caso acredite su derecho, conforme al mentado Art. $9^{\circ}$ del Código Procesal Constitucional.

Respecto de un asunto de carácter formal, vinculado con la naturaleza de la copia a presentar, debe tenerse presente que está vedada la presentación de copias simples, salvo que corresponda a un documento que corroborará otro que haya sido presentado en original o en copia legalizada o fedateada.

Al inicio de este acápite enfatizábamos la existencia de dos pensiones: jubilación e invalidez. Al respecto debe repararse en que se trata de dos pensiones distintas, que atienden dos riesgos distintos y que están financiadas por fuentes distintas, razones que conducen a que no se acepte extrapolar instituciones diseñadas para una de ellas a favor (o mejor diré, en su perjuicio) de otra.

Una de ellas es la fijación de topes máximos y mínimos que corresponde a la pensión de jubilación. Por su distinta naturaleza, ya explicitada supra, no cabe trasladar ambos topes a la pensión de invalidez, razón por la cual se declaran fundadas aquellas demandas que exigen a la Oficina de Normalización Previsional (en adelante, la ONP) no imponer un tope máximo a la pensión de invalidez.

Respecto de la pensión de invalidez, el TC estableció como precedente vinculante que la 
única instancia habilitada para determinar la invalidez de una persona es la Comisión Médica Evaluadora de Incapacidades de EsSalud, del Ministerio de Salud o de las Entidades Prestadoras de Servicios (EPS), comisión que expide un dictamen debidamente suscrito por sus tres miembros, razón por la cual se declaran infundadas las demandas que carezcan de la presentación de dicho dictamen o que se presente un dictamen con la firma de solo uno o dos miembros de la referida comisión.

Asimismo es usual revisar demandas en las que se solicita pensión de invalidez en atención a un diagnóstico médico (de las características aludidas supra) de fecha largamente posterior a aquélla en que ocurrió la contingencia, de ahí que se declaren infundadas las demandas en las que se solicita pensión de invalidez por hipoacusia (exposición prolongada al ruido), por citar un ejemplo, cuando media más de 10 años entre la fecha del cese laboral (contingencia) y la fecha del diagnóstico médico, y es que el transcurso del tiempo evidencia la ausencia de una relación de causa-efecto entre las labores desempeñadas y la dolencia diagnosticada.

Por otro lado se suelen interponer amparos previsionales que tienen como propósito reactivar el pago de la pensión de invalidez que ha sido suspendido por la ONP debido a que la justicia penal ha determinado que antiguo personal de la ONP en su condición de verificadores participó en una asociación ilícita que validaba indebidamente documentación impertinente a efecto de obtener su pensión.
Las peculiares características de cada caso en concreto originan que la declaración de la demanda como fundada o infundada dependa de la conexión existente entre el accionar de aquellos ex trabajadores de la ONP y el expediente del recurrente, y es que son numerosos los casos en que pese a que no existía conexión alguna entre ambos factores, la ONP suspendía el pago de la pensión, decisión que al no estar motivada se declaraba como nula y por ende, se declaraba fundada la demanda.

Finalmente me referiré a las demandas que persiguen el retorno del recurrente del Sistema Privado de Pensiones al Sistema Público de Pensiones. Se rechazan aquéllas de las que se desprende que no se ha agotado la vía previa, es decir, en las que no se ha acudido a la Superintendencia de Banca, Seguros y AFP's (SBS), igualmente se declara la improcedencia de las demandas presentadas por recurrentes que ya son pensionistas.

Como quiera que en este supuesto puede afectarse el derecho al debido procedimiento, como por ejemplo la perpetración de una eventual arbitrariedad de la ONP como emitir un Reporte de Situación (RESIT) del recurrente en el que no se compute adecuadamente los años de aportación sustentados, pues al ser diminutos daría lugar a la denegación del retorno solicitado, estamos ante un caso en el que el derecho afectado no es el derecho a la pensión sino, insisto, el derecho al debido procedimiento, razón por la cual sí es posible detectar un acto lesivo y en función de ello verificar si ha transcurrido o no el plazo prescriptorio previsto en el Art. $44^{\circ}$ del Código Procesal Constitucional.

Esta observación no es gratuita pues el TC ha considerado que en los amparos previsionales en los que se alegue la vulneración del derecho a la pensión, dada su naturaleza alimentaria, no corre el plazo del Art. $44^{\circ}$ del Código Procesal Constitucional.

\section{ACCIONES DE AMPARO CONTRA} RESOLUCIONES JUDICIALES Y OTROS

Como se sabe mediante este amparo se persigue declarar la nulidad de una resolución judicial que se ha expedido con infracción al derecho al debido proceso, ya sea por ausencia de motivación, por haberse producido la indefensión del recurrente al no haber sido adecuadamente notificado con alguna resolución judicial, entre otros supuestos.

Sin embargo lo que ocurre en la práctica es que en una gran mayoría de casos, lo que realmente se pretende es el reexamen del proceso respecto del cual se ha dictado la resolución judicial objeto del amparo, para lo cual se busca una nueva revaloración de los medios probatorios actuados en el proceso, o se pretende prolongar indefinidamente el efecto de diversas argucias o articulaciones procesales que, en el proceso subyacente, fueron debidamente rechazadas. En este caso es de aplicación el Art. $5.1^{\circ}$ del Código Procesal Constitucional.

Por otro lado, a diferencia del plazo prescriptorio general de 60 días hábiles previsto en el Art. $44^{\circ}$ del Código Procesal Constitucional, la acción de 
amparo contra resoluciones judiciales prescribe luego de los 30 días hábiles de producido el acto lesivo, en este caso, la resolución judicial cuestionada. Ahora bien, el Código adjetivo especifica que el referido plazo se comienza a contar desde que se expide la resolución que dispone cumplir lo ejecutoriado, de manera tal que antes que enfocarse en la fecha de la resolución judicial cuestionada, a fin de verificar el inicio del plazo prescriptorio, habría que atender a la fecha del cúmplase.

Sin embargo, esta disposición ha sido interpretada por el TC como aplicable en aquellos casos en los que la resolución judicial cuestionada dispone una prestación de dar o de hacer. Así, no basta con dicha resolución sino que se requiere de un cúmplase para que efectivamente se realice la prestación ordenada por mandato judicial; contrario sensu, si estamos frente a una resolución judicial que no dispone una prestación positiva, no habiendo nada que cumplir, no será necesario que se expida el cúmplase y por ende, en ese caso el plazo prescriptorio se iniciará con la resolución judicial cuestionada.

Por otro lado, es frecuente la presentación de amparos por parte de: i) autoridades municipales que fueron suspendidos, destituidos o vacados del ejercicio de sus cargos por mandato judicial o del Jurado Nacional de Elecciones, ii) dirigentes de asociaciones que fueron retirados de sus cargos por dispo- sición de la asamblea general respectiva; iii) postulantes a concursos públicos de méritos para ocupar plazas en el Poder Judicial, Ministerio Público, en la carrera pública magisterial, entre otros. Debo precisar que en todos estos casos se arguye la infracción al debido proceso como supuesto habilitante para que actúe la jurisdicción constitucional $^{2}$.

Ante la dilación que se observa en la tramitación de los procesos de amparo en sede judicial y la carencia normativa del amparo directo ante el $\mathrm{TC}^{3}$, ocurre que los amparos no se resuelven oportunamente y, simultáneamente, van venciendo el período para el cual fueron elegidos las autoridades municipales o los dirigentes de la asociación a que hemos aludido supra, así como se van eligiendo a sus reemplazantes, razón por la cual, cuando el expediente sube al TC, éste constata la irreparabilidad del agravio producido y declara la improcedencia de la demanda. Respecto al supuesto de los concursos cabe añadir que, además de la irreparabilidad producida por la cobertura de la plaza a cargo de quien la ganó, opera el principio de preclusión de las etapas que conforman el concurso, de modo tal que ya no es posible retrotraer el concurso a etapas ya vencidas.

\section{ACCIONES DE CUMPLIMIENTO}

Antes de ingresar a analizar el fondo de la controversia presen- tada en una acción de cumplimiento es menester revisar si el recurrente cumplió con remitir al emplazado un documento de fecha cierta (v.gr. una carta notarial) solicitándole el cumplimiento de una norma legal o de un acto administrativo y que este último haya persistido en su incumplimiento o no hubiese contestado luego de 10 días hábiles de recibido dicho documento, conforme al Art. $69^{\circ} \mathrm{del}$ Código Procesal Constitucional. Luego, debe verificarse que la demanda se haya interpuesto dentro de los 60 días de recibido dicho documento, según el Art. $70.8^{\circ}$ del Código Procesal Constitucional.

Hago notar que el Código adjetivo ha previsto como hito de inicio del plazo prescriptorio de la acción de cumplimiento a la fecha de recepción del documento de fecha cierta que contiene el reclamo previo y no a la fecha de vencimiento del plazo de 10 días que tuvo el emplazado para dar cumplimiento a lo que se solicitó mediante dicho documento.

Por otra parte, los supuestos más frecuentes de acción de cumplimiento coinciden con las condiciones de procedibilidad adicionales que fueron impuestas por el TC mediante la STC 168-2005$\mathrm{PC} / \mathrm{TC}$, de ahí que se suelen interponer demandas en las que no está vigente el mandato de la norma cuyo cumplimiento se reclama (v.gr. resolución regional que concede un beneficio al personal que ha sido derogada por el Gobierno Regional entrante),

2 Pues no podría alegarse, por citar el supuesto ii), la mera impugnación del acuerdo de la asamblea general en la medida que existe una vía ordinaria alternativa y satisfactoria para restablecer el ejercicio del derecho vulnerado, como es el proceso civil de impugnación de acuerdos.

3 Véase una posición a favor del amparo directo ante el TC en URVIOLA, Óscar: El amparo directo. Suplemento Jurídica del diario oficial El Peruano. 22 de mayo de 2012. 
o que no está individualizado el derecho del recurrente, esto es, carece de un mandato indubitable a su favor (quien se aferra a una norma legal que aparentemente lo beneficiaría, pero no cuenta con un acto administrativo que estime que le es de aplicación lo prescrito en dicha norma legal), o que el mandato de la norma revista complejidad (v.gr. solicitudes del otorgamiento de una pensión que está condicionada a la previa determinación del cumplimiento de la edad requerida y los años de aportaciones exigibles), entre otros supuestos.

\section{HáBEAS DATA}

Al igual que en la acción de cumplimiento debe revisarse previamente si el recurrente cumplió con remitir al emplazado un documento de fecha cierta reclamándole el respeto de los derechos protegidos por el hábeas data (acceso a la información que obra en poder de una entidad pública y conocimiento y eventual corrección de información que consta en bases de datos de entidades públicas o privadas) y que este último haya persistido en su incumplimiento o no hubiese contestado luego de 10 días hábiles de recibido dicho documento, de acuerdo con el Art. $62^{\circ}$ del Código Procesal Constitucional.

Ahora bien, a diferencia de la acción de cumplimiento, en el Código adjetivo no se precisa, literalmente, un plazo prescriptorio del hábeas data, lo que podría conllevar a concluir que el recurrente goza de un plazo infinito para interponer su demanda luego de que venciera el plazo de 10 días que tuvo el emplazado para acceder a lo que se solicitó mediante el documento de fecha cierta.

Sin embargo esa interpretación no se condice con el régimen general en materia de prescripción planteado para las acciones de garantía, que impone un plazo, a fin de que la controversia jurídica se esclarezca en un término verificable y no se mantenga irresoluta. Atendiendo adicionalmente a que el régimen procedimental de la acción de amparo es supletorio al del hábeas data, según el Art. $65^{\circ}$ del Código Procesal Constitucional, es válido sostener que esta última debe interponerse dentro de los 60 días hábiles de producido el acto lesivo (la denegación de la información solicitada, la ausencia de pronunciamiento del emplazado o el vencimiento del plazo), conforme al Art. $44^{\circ}$ del Código Procesal Constitucional.

\section{Conclusión}

De esta manera se han repasado en este artículo los casos más frecuentes que conoce el TC con la intención de identificar algunos lineamientos básicos que el operador del derecho debe identificar y satisfacer, de ser el caso, antes de acudir a la jurisdicción constitucional, así como la detección de aquellos supuestos en los que es predecible el juicio de fondo por parte del TC. 